\title{
ENTRE FOUCAULT E MBEMBE: da biopolítica à necropolítica no século XXI ${ }^{1}$
}

\section{Between Foucault and Mbembe: from biopolitics to necropolitics in the 21st century}

\author{
Glícia Édeni de Lima Teixeira ${ }^{2}$
}

Ramiro Ferreira de Freitas ${ }^{3}$

\section{RESUMO}

Este trabalho pretende revisitar o pensamento teórico do filósofo francês Michel Foucault, o qual continua a inspirar estudos científicos e mesmo a antever os próprios rumos da sociedade. Suas reflexões, que tratam de relações de poder e dominação, costumam transitar entre os campos da sociologia, filosofia e política e possuem grande aceitação na atualidade. Esta pesquisa tem como objetivo demonstrar que os conceitos foucaultianos formulados nos anos de 1970, a exemplo do termo biopolítica, inspiram novas gerações de pensadores, como o intelectual camaronês contemporâneo Achille Mbembe. Este autor amplia a discussão proposta por Foucault e inaugura a conceituação de necropolítica, a qual considera elementos como vida e morte enquanto traços sociopolíticos, além de representar importante indicativo para a compreensão social contemporânea. Mbembe complementa os estudos de Foucault, visto que considera o conceito de biopolítica insuficiente para ilustrar as práticas pelas quais o poder político executa a aniquilação de indivíduos ou mesmo populações consideradas como inimigas dos interesses do Estado. Quando os movimentos governamentais "fazem viver" ou "deixam morrer", subscrevem o comando pela força violenta de ações, por vezes, injustificadas. Este trabalho utiliza metodologia e procedimento bibliográficos, bem como possui abordagem qualitativa e exploratória. Destaca-se que a pesquisa teórica consiste em uma revisão narrativa, incluindo-se além dos livros e periódicos científicos, fontes como notícias e ainda textos legais a respeito do tema. Este estudo aponta como resultado a notória influência do pensamento foucaultiano acerca de questões sociológicas da contemporaneidade. Enquanto conclusão desta pesquisa, aponta-se a necessidade de que a discussão de Aquille Mbembe sobre necropolítica ultrapasse os limites das nações subdesenvolvidas e historicamente subjugadas por seus colonizadores. Desta maneira, os estudos de Mbembe devem indicar os rumos de uma agenda mundial capaz de dignificar a existência de populações empobrecidas por meio de processos históricos avassaladores de exploração e extermínio de pessoas em condição de vulnerabilidade social.

Palavras-chave: biopolítica. Foucault. necropolítica.

\begin{abstract}
This work aims to revisit the theoretical thinking of the French philosopher Michel Foucault, who continues to inspire scientific studies and even foresee the very directions of society. His reflections, which deal with relations of power and domination, usually move between the fields of sociology, philosophy and politics and have great acceptance today. This research aims to demonstrate that the Foucaultian concepts formulated in the 1970s, like the term biopolitics, inspire new generations of thinkers, such as the contemporary Cameroonian intellectual Achille

\footnotetext{
${ }^{1}$ Subvertemos a concordância entre os autores deste ensaio, que não existe. O próprio manuscrito é uma aventura colegial, pelo que o leitor é advertido quanto à noção irrefletida de nossos apontamentos, barulho à laise.

${ }^{2}$ Universidade Regional do Cariri - URCA. E-Mail: emaildaglicia@gmail.com

${ }^{3}$ Universidade Regional do Cariri-URCA. E-Mail: ramiroferreira91@gmail.com
} 
Mbembe. This author expands the discussion proposed by Foucault and inaugurates the concept of necropolitics, which considers elements such as life and death as socio-political traits, in addition to representing an important indicator for contemporary social understanding. Mbembe complements Foucault's studies, as he considers the concept of biopolitics insufficient to illustrate the practices by which political power executes the annihilation of individuals or even populations considered to be enemies of the State's interests. When government movements "make it live" or "let it die", they subscribe to the command by the violent force of actions, sometimes unjustified. This work uses bibliographic methodology and procedure, as well as a qualitative and exploratory approach. It is noteworthy that the theoretical research consists of a narrative review, including in addition to books and scientific journals, sources such as news and even legal texts on the subject. This study points out as a result the notorious influence of Foucault's thinking on contemporary sociological issues. As a conclusion of this research, it points out the need for Aquille Mbembe's discussion on necropolitics to go beyond the limits of underdeveloped and historically subjugated nations by their colonizers. In this way, Mbembe's studies must indicate the direction of a world agenda capable of dignifying the existence of impoverished populations through overwhelming historical processes of exploitation and extermination of people in conditions of social vulnerability.

Keywords: biopolitics. Foucault. necropolitics.

\section{Introdução}

O pensador francês Paul-Michel Foucault (1926 - 1984) representa um dos maiores expoentes intelectuais no século XX. Seu gênio transgressor e inquieto levou-o a dedicar-se ao estudo de temáticas como certos mecanismos de controle social e relações de poder, além de peculiaridades da chamada sociedade disciplinar. Suas pesquisas apontam que o Estado moderno se ocupa com a dominação e a modulação dos corpos humanos a fim de transformá-los em verdadeiras máquinas dóceis e úteis.

Neste sentido, Michel Foucault levantou apontamentos sobre a forma que o poder sociopolítico condiciona a vida dos indivíduos sob seu domínio. Dentre as observações contidas em suas obras, o autor defendeu que muitos daqueles socialmente segregados como loucos ou indigentes são, na realidade, vítimas de uma exclusão institucional orquestrada e promovida pelo sistema dominante.

Influenciado pelo pensamento de Foucault no que diz respeito a temas como biopolítica, o filósofo camaronês contemporâneo Joseph-Achille Mbembe desenvolveu a teoria da necropolítica. O autor ratifica a tese foucaultiana de que os poderes políticos presentes na atualidade intentam controlar a vida e os atos dos seres humanos. Achille Mbembe então amplia o conceito foucaultiano de biopolítica ao defender que o controle estatal apontado se estende 
inclusive sobre a morte daqueles considerados inadequados ou incômodos em determinado contexto social.

Desta forma, Achille Mbembe aprofunda os estudos de Foucault e indica uma evolução da teoria biopolítica no sentido de transformar-se em uma realidade necropolítica. Em seus estudos, Mbembe justifica esta teoria ao relacioná-la a determinadas problemáticas comumente observadas em países que sofreram processos de colonização, como regimes de escravidão e dominação por parte de seus exploradores, especialmente nos continentes africano e americano.

Este artigo não pretende esgotar a discussão sobre a teoria biopolítica elaborada por Michel Foucault, tampouco encerra as inquietações levantadas por Achille Mbembe quanto aos seus estudos sobre o conceito de necropolítica. Com esta pesquisa se pretende traçar um breve paralelo entre as citadas teses destes autores, aproximando-as no que diz respeito às realidades sociais e políticas presentes no século XXI, especialmente nos chamados países de terceiro mundo.

De fato, a teoria biopolítica foucaultiana continua válida no contexto sociopolítico dos tempos atuais. Este período histórico confirma ainda a teoria necropolítica, que possui o racismo como mola propulsora, segundo Achille Mbembe. Desta maneira, pode-se observar a força do poder necropolítico dominar as regiões periféricas das nações mais empobrecidas historicamente. Realidades sociais contemporâneas como a multiplicação de moradias precárias ocupadas por populações famintas, desempregadas e excluídas de quaisquer oportunidades de vida são capazes de comprovar a implementação bem sucedida da necropolítica no contexto social do século XXI.

\section{A biopolítica segundo Michel Foucault}

O filósofo Paul - Michel Foucault nasceu na cidade francesa de Poitiers em 15 de outubro de 1926. Considerado um dos mais importantes pensadores do século XX, Foucault continua a exercer influência sobre pesquisadores de diferentes áreas do conhecimento, como filosofia, sociologia, história, psiquiatria, dentre outras.

Oriundo de família tradicional de médicos, Foucault rebelou-se ao optar por dedicar-se ao estudo de ciências como História, Psicologia e Filosofia. O teórico debruçou-se, então, sobre temáticas como loucura, a sexualidade humana enquanto método de controle social, bem como as relações de poder e como estas se desenvolvem em sociedade. Paul-Michel Foucault faleceu 
aos 57 anos em decorrência de complicações causadas pela AIDS na cidade de Paris em junho de 1984.

Em seus estudos, Foucault elaborou conceitos e neologismos a fim de classificar os fenômenos e comportamentos sociais observados na contemporaneidade. A expressão "biopolítica" representa uma destas notáveis colaborações foucaultianas para o pensamento crítico no século XX. Elaborado pelo autor na década de 1970, o termo biopolítica é definido pela filósofa francesa Judith Revel (2005, p. 26) como

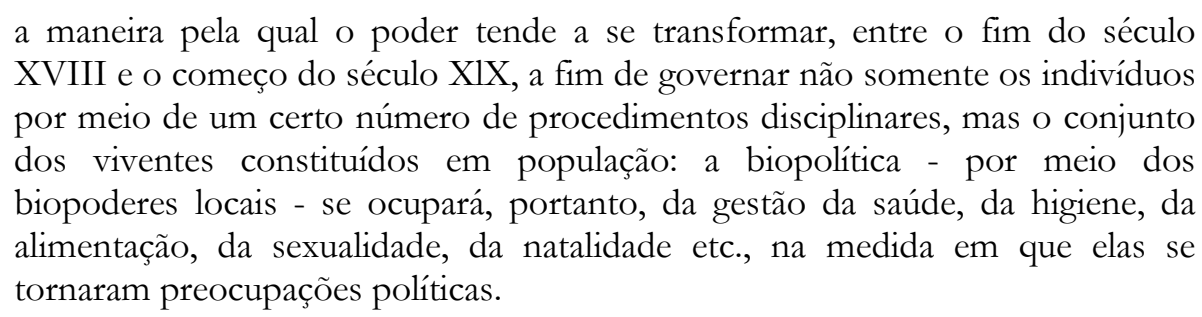

Desta forma, a biopolítica representa o esforço despendido pelo Estado na intenção de controlar a vida biológica humana em favor de seus interesses. De acordo com o autor, as relações de poder como as conhecemos na atualidade começaram a ser delineadas em meados do século XVIII. Com a expansão da revolução industrial, o consequente crescimento do regime capitalista se deu entre os séculos XVI e XX: os industriais passaram então a manter verdadeiros exércitos de trabalhadores nas linhas de frente de produção nas fábricas.

\subsection{Das relações de poder no estado moderno}

Michel Foucault leciona que o Estado moderno impôs o poder disciplinar na esfera individual. Por outro lado, no que diz respeito à comunidade, inaugurou-se o que se conhece como sociedade contemporânea. Neste meio coletivo, o poder é algo que se exerce de maneira ampla, por meio de discursos, de gestos e de atos que não se restringem às classes dominantes. De acordo com Foucault, o poder organiza-se de forma reticular, de modo que esta teia composta por micropoderes perpassa todo o tecido social.

Por sua vez, a crescente automatização dos meios de produção nas últimas décadas ocasionou mudanças significativas no modo de trabalho na sociedade capitalista: desta maneira, o sistema passou a demandar cada vez menos de força de trabalho. Neste sentido, observou-se massivamente ao final do século XX um verdadeiro descarte de populações produtivas: a coletividade humana passou a encarar problemas como o desemprego estrutural. Esta realidade enfrentada pelos indivíduos pode comprometer o sentido da vida, desencadear um vazio existencial e favorecer o surgimento de patologias, como quadros de depressão, por exemplo. 
Neste ínterim, o Estado moderno pôs-se a empurrar as comunidades mais vulneráveis para as periferias dos centros urbanos, onde facilmente se tornam alvos da violência policial e do encarceramento em massa. A este respeito, o professor Fernando Danner (2010, p. 02) leciona que

Para Foucault, a constituição do Estado moderno, com a gênese e o desenvolvimento das novas relações de produção capitalistas, leva à instauração da anátomo-política disciplinar e da biopolítica normativa enquanto procedimentos institucionais de modelagem do indivíduo e de gestão da coletividade; em outras palavras, de formatação do indivíduo e de administração da população.

Publicada em 1975, a obra Vigiar e punir defende que as relações de poder representam uma constituição microfísica, além de incidir sobre os corpos dos indivíduos, de modo que todos sejam perpassados por estas relações. Segundo Foucault, o poder "se exerce mais que se possui" e o poder exercido nesta teia microfísica não deve ser encarado como propriedade, mas como uma estratégia. (FOUCAULT, 1987, p. 30)

Neste sentido, o autor afirma que o corpo individual adentra em certa "maquinaria de poder que o esquadrinha, o desarticula e o recompõe”. (FOUCAULT, 1987, p. 164) Esta técnica de dominação social pode ser observada de forma mais clara no âmbito de instituições como escolas e quarteis generais, presídios e hospitais. O poder disciplinar, representa desta forma um poder de vigilância e controle sobre a vida dos indivíduos. Neste sentido, este poder disciplinar descrito por Foucault dociliza e impõe o enquadramento dos corpos considerados inadequados. Desta maneira, o antigo poderio de morte da soberania é substituído pela "administração dos corpos" e a "gestão calculadora da vida". (HILÁRIO, 2016, p. 199)

Apesar do tom pessimista que permeia a obra de Foucault, o autor defende no livro Vigiare punir (1987, p. 218) que o poder deve ser visto também como algo positivo, capaz de criar sabedoria e agregar conhecimento:

Temos que deixar de descrever sempre os efeitos de poder em termos negativos: ele "exclui", "reprime", "recalca”, "censura", "abstrai", "mascara", "esconde". Na verdade, o poder produz; ele produz realidade; produz campos de objetos e rituais da verdade. O indivíduo e o conhecimento que dele se pode ter se originam nessa produção.

\subsection{Da disciplina:}

Michel Foucault nomeia como disciplina os métodos que docilizam os corpos a fim de que estes se tornem obedientes e produtivos. Para este, a disciplina inicialmente procede à distribuição dos indivíduos. Foucault cita como "cerca" a especificação de um local heterogêneo 
a todos os outros e fechado em si mesmo, como colégios e quartéis. O autor cita ainda que houve um grande encarceramento de indivíduos vagabundos e miseráveis como forma de controle social estatal. (1987, p. 168)

Foucault leciona que tais métodos que proporcionam ao Estado o controle dos corpos, sujeitam as forças dos indivíduos de modo contínuo. O autor explicita ainda a existência de processos disciplinares muito antigos que se desenvolvem em ambientes que favorecem o controle e a dominação da coletividade. O filósofo, então, nomeia como disciplinas determinadas técnicas de aplicação do poder que se tornaram fórmulas de dominação estatal a partir do século XVII.

Judith Revel (2005, p. 35) expressa que o regime disciplinar descrito por Foucault pretende desde alocar os corpos em ambientes estratégicos até controlar suas ações e padrões comportamentais. A autora leciona que este regime disciplinar apontado por Foucault

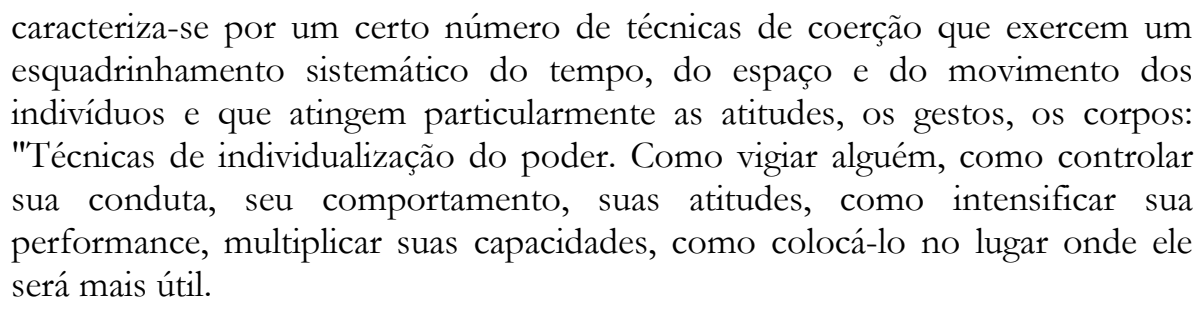

Ainda sobre as disciplinas, é razoável afirmar que estas não constituem invenção própria da sociedade moderna, mas se fazem presentes desde tempos imemoriais em ambientes como asilos, hospitais, conventos e quartéis generais. Judith Revel aponta que, na realidade, Foucault "procura compreender de que maneira elas tornaram-se, num determinado momento, fórmulas gerais de dominação.” (REVEL, 2005, p. 35)

Foucault afirma que os elementos das disciplinas são "intercambiáveis, pois cada um se define pelo lugar que ocupa na série, e pela distância que o separa dos outros.” (1987, p. 172) Neste sentido, as disciplinas são técnicas essenciais na modelação de corpos dóceis e úteis ao Estado. Segundo Ferreirinha e Raitz “as análises de Foucault das instituições não são uma crítica pura, mas trazem reflexões aos sistemas instituídos no interior delas, à medida que ocorre sua progressão histórica. A ordem disciplinar, como vista, perfaz uma forma de instituir ordem e alçar eficiência e utilidade econômica.” (FERREIRINHA E RAITZ, 2010, p. 380)

De acordo com Foucault (1987, p. 192), a disciplina é capaz de produzir quatro tipos de individualidade, ou uma individualidade na qual se distinguem as seguintes características: "é celular (pelo jogo da repartição espacial), é orgânica (pela codificação das atividades), é genética 
(pela acumulação do tempo), é combinatória (pela composição das forças)". Ainda segundo o autor, a disciplina utiliza quatro grandes técnicas a fim de produzir tais individualidades. Portanto, a disciplina "constrói quadros; prescreve manobras; impõe exercícios; enfim, para realizar a combinação das forças, organiza "táticas"."

\subsection{Do panoptismo}

No (supra referido Vigiar e punir, Michel Foucault dedica-se ao estudo do dispositivo Panóptico, desenvolvido pelo pensador inglês utilitarista Jeremy Bentham ao final do século XVIII. Tal dispositivo arquitetônico visa concretizar o ideal estatal de observação absoluta sobre os condenados ocupantes do sistema penitenciário. Constituído por um espaço circular fechado e composto por celas e torre central, esta arquitetura foi planejada de maneira que todas as celas possam ser observadas sob o ponto de vista do vigilante. Por sua vez, os ocupantes das celas individualizadas não conseguem comunicar-se com os demais companheiros e tampouco perceber em quais momentos estão sendo vigiados da torre.

Michel Foucault utiliza o ideal do dispositivo Panóptico como analogia para explicar a vigilância a que o Estado submete os indivíduos na contemporaneidade: desta forma, o autor analisa determinadas instituições disciplinares sob a perspectiva da arquitetura do Panóptico idealizado por Bentham. Foucault compara, então, esta arquitetura a um jardim zoológico: “O Panóptico é um zoológico real; o animal é substituído pelo homem, a distribuição individual pelo grupamento específico e o rei pela maquinaria de um poder furtivo.” (1987. p. 226)

Foucault descreve ainda o Panóptico como "uma máquina maravilhosa que, a partir dos desejos mais diversos, fabrica efeitos homogêneos de poder.” (1987, p. 25) O filósofo observa que a relação fictícia forjada pelo Panóptico garante ao Estado uma sujeição real de caráter artificial, mecânico. O autor leciona que, desta forma, "não é necessário recorrer à força para obrigar o condenado ao bom comportamento, o louco à calma, o operário ao trabalho, o escolar à aplicação, o doente à observância das receitas." (1987, p. 226)

A teoria biopolítica desenvolvida por Foucault oferece fundamentos para um controle estatal de cunho necropolítico, conforme descrito pelo pensador camaronês contemporâneo Achille Mbembe. Neste contexto, uma política voltada para o controle dos indivíduos, de modo a adequá-los socialmente, evolui naturalmente para uma política estatal cujo objetivo é a aniquilação em larga escala de corpos considerados subversivos ou inúteis para o sistema dominante. 


\section{Achille Mbembe e a teoria da necropolítica}

O Terceiro Mundo é uma zona "cinzenta" na qual se travam batalhas pelo controle. Os "desenvolvidos" controlam os corpos e as nações dos "outros", gerenciando mortes. Mbembe contribui com sua razão pensada racial, materialista e crítica ao processo colonial. Professor hoje na África do Sul, o autor questiona imposições coercitivas de força e menciona a soberania como elemento político - e política é transgressão - não absolutamente positivo. O "deixar morrer" (PEREIRA, 2019) não acha-se somente nas câmaras de gás nazistas (durante a II Grande Guerra), mas no alegado estado de exceção ocidental propulsor do extermínio.

O progresso tecnológico constitui outro resultado da centralização ideológica da ordem legal, pois os ataques, o terrorismo e mísseis balísticos de distintos alcances representam gradações na capacidade de tirar vidas, impondo necessariamente uma virtual cerca sobre quem é visto, pelos sistemas globais, como descartável.

Os “diagramas” mandantes, ou melhor, que definem os 'líderes' e 'subordinados,' são intersecções entre Foucault e Mbembe. A Necropolítica é uma Necropolítica. "Na verdade, o que subjaz as reflexões sobre biopoder-biopolítica está - antes de tudo - na forma como o poder passa então a ser entendido: não mais a partir de grandes teorias, mas em sua dimensão e mecanismos microcapilares." (KIMA, s-d, p. 21)

Logo, se a disciplina reside em manter uma população adaptada aos seus padrões estruturalmente ordenada por mecanismos vitais (bios), é conveniente subscrever o maniqueísta fenômeno da mortalidade (thanatos) notável glória do soldado ou derrota em combates

inferiorizantes. É imperioso rever epistemologias, mas, a proteção de minorias não pode esquecer projeções históricas fundadas em modelo democrático que foi, em algum momento, tacitamente aceito pela coletividade (precarização existencial refletida em genocídios e na perversidade resgatada pela velha gramática perversa, suscitada no e pelo não-dito). "Partindo desse contexto, a bionecropolítica à brasileira se constituiu de forma diaspórica, assimétrica, opressora, violenta, genocida e racista porque "em larga medida o racismo é o motor do princípio necropolítico" (Mbembe, 2017, p. 65).” (LIMA, s-d, p. 23) Aqui o negro é vitimizado, colocado abaixo das intenções assassinas de um Estado (branco) opressor. Não é objetivo deste breve escrito trazer à luz o inteiro teor do biopoder (as obras dos autores devem ser consultadas e mesmo estudiosos foucautianos tergiversam quanto à matéria) mas cabe um tingimento crítico no que refere o 
“ordenamento burguês" sendo este parcialmente fomentador dos mesmos dogmas (propriedade, liberdade, normas) e, em simultâneo escopo, modificador de realidades pré-modernas. Será ele o único culpado das mazelas sociais?

Entendemos haver aí questão relevante. Que há desigualdade, acredita-se, ninguém contestará, porém, o intuito das desagregações não foi, historicamente, binário. Dentro dos grupos tradicionais, em povos originários, existem conflitos. Os autores "anti-eurocêntricos" são, geralmente, europeus ou formados segundo matrizes teóricas fundamentalmente "eurofílicas"4. Logo, corre-se o risco de contaminar informação com uma estreita interpretação legitimada pelos territórios distantes mas, preparada nos gabinetes universitários e nas salas de aula urbanas. Isso não desqualifica as grandes produções intelectuais dos projetos emancipatórios, bem diferentemente, reforça o relevante pluralismo ${ }^{5}$ merecedor de cultivo.

O cientista social, logo, deve pautar-se pela busca propriamente dos fatores implicados na vitalidade social, não "escolhendo" arbitrariamente um partido hipotético anacrônico. Os massacres são processos antigos. Tanto em Roma quanto na Papua-Nova Guiné o soberano é autorizado a eleger pessoas mais ou menos dignas. Deixar-se inebriar por emoções locais é arriscado caminho capaz de obnubilar assimetrias oriundas da conjuntura e não de indivíduos ou classes isoladas.

O "buraco" (ou sepulcro?) no qual estão encerradas as temíveis podridões ocultas no regime autoritário existe como aparência finita de um limite menos claro, mais florido pelo discurso cerimonial. Quer-se reviver, mas o morrer insiste. Quer-se nascer, mas a contradição do interrompido vem como natimorto ao ventre! Aqueles(as) que compartilham da filosofia cínica são uma negação, ao mesmo tempo, de si mesmo e do homem que vê-no-mundo. O Espírito da Vida (Geist des Lebens) invocado por Mbembe lubrificou a inquietação dos vivos com relação a seriedade, é a única adjetivação que tem postura discursiva tranquila. Falar em violência, em

\footnotetext{
${ }^{4}$ Mbembe, nos informa Lima (s-d), é nascido em julho de 1957 nos Camarões (três anos antes da Independência da República dos Camarões - 1960), fez sua formação acadêmica inicialmente na França e, posteriormente, em Nova Iorque, nos EUA.

${ }^{5}$ Caberia, nesta sede, uma nota personalíssima e que não deve confundir o leitor, tomando como premissa outra agudez metodológica, noutro giro cognitivo. O texto de Schnorr (2019) sobre interculturalidade e libertação é ótimo parâmetro. Não obstante - e sem nenhuma pretensão de refutar a autora - tenho muita dificuldade de compreender a ideia decolonial, no sentido de, apesar dos pesares, nossa sociedade (ocidental) e o fazer filosófico (como "estilo de vida") típico dessa racionalização (do homem que 'ama ' um certo tipo de sabedoria) serem o que são graças, justamente, aos colonizadores. Não estou dizendo que os continentes explorados deixam de produzir consciência, mas, até mesmo a crítica à Europa é, como acabamos de dizer, em grande medida, europeia... Isso seria contraditório, com tons de manutenção ambivalente... Como pensar o mundo de outra forma se não formos os 'outros'? Talvez por isso os movimentos sociais às vezes sofram acusações de "interessados em segmentos específicos" (o que, guardadas proporções, é verdade) mormente no que diga respeito a coletivos.
} 
condições de manutenção orgânica e no que não depende da gente - a saber, o natural - tem muito a ver-ouvir-tocar através do sistema pseudoinclusivo (base do caos).

\section{Considerações Finais}

Reter, no fechamento, a vaidade de um rosto abstrato, é conceber as unidades e agenciamentos como muros superficiais (data geral em referência na tela). Acusar e ser acusado, exercer poder e ser em torno dele suprimido é discernir o "outro" intuído. Foucault e Mbembe são esses “inéditos”, viáveis só em certo nível reduzido.

Não para de crescer a loucura (na clínica, no divã e na cova). Quem só pôs os pés nesse terreno movediço há de reconhecer-se perante terremoto desviante. Nosso escorço é mediano, sem peias nem marotas seriedades. Tristemente integrado, o excêntrico ocidente promove o gueto e desencarna corpos, suga a seiva e bebe o sangue, queima o vegetal e extingue (devorando ou derrotando) o animal. Sempre escapa ao senso, não é cartesiano puro, mas desvairado afrontoso.

Cá, nesta sinuosa viragem, o dueto evapora. Solidificados, mudam para sutil digitalização, tempestade afetiva tributa um anúncio fúnebre: O VELHO MUNDO ESTÁ DEFUNTO! E jaz seu corpo no estrume dos sujeitos.

\section{REFERÊNCIAS}

ALBUQUERQUE JÚNIOR, Durval Muniz. O pensador de todas as solidões. Editora Segmento. Foucault pensa a Educação, São Paulo, v. 3, 2008.

DANNER, Fernando. O Sentido da Biopolítica em Michel Foucault. Revista Estudos Filosóficos, $\mathrm{n}^{\circ} 4$ /2010 - versão eletrônica - ISSN 2177-2967 Disponível em: http://www.ufsj.edu.br/revistaestudosfilosoficos Acesso em 10. Set. 2020.

FERREIRINHA, Isabella Maria Nunes. RAITZ, Tânia Regina. As relações de poder em Michel Foucault: reflexões teóricas. Revista de administração pública. RAP — Rio de Janeiro 44(2):367-83, MAR./ABR. 2010. 
FOUCAULT, Michel. Vigiar e punir: nascimento da prisão; tradução de Raquel Ramalhete. Petrópolis, Vozes, 1987.

GRISOSKY, Daniela Cecília; PEREIRA, Bruno César. Da biopolítica à necropolítica: notas sobre as formas de controles sociais contemporâneas. In: Espaço acadêmico, vol. 20, n. 224, pp. 199-208, 2020.

HILÁRIO, Leomir Cardoso. Da biopolítica à necropolítica: variações foucautianas na periferia do capitalismo. In: Sapere aude - Belo Horizonte, v. 7 - n. 12, p. 194-210, jan. /jun. 2016 ISSN: $2177-6342$

LIMA, Fátima. Bio-necropolítica: diálogos entre Michel Foucault e Achille Mbembe. In: Arquivos brasileiros de psicologia, n esp. 70, pp. 20-33, s-d.

PEREIRA, Juliana Martins. [resenha] MBEMBE, Achille. Necropolítica. 3. ed. São Paulo: n-1 edições, 2018. 80 p. In: Horizontes antropológicos, a. 25, n. 55, pp. 367-371, 2019.

REVEL, Judith. Michel Foucault: conceitos essenciais. São Carlos: Claraluz, 2005.

SCHNORR, Gisele Moura. Inéditos viáveis: dialogicidade, interculturalidade e libertação. In: Revista do NESEF, vol. 8, n. 1, pp. 24-46, 2019. 